\title{
Bilateral and unilateral mesodermal corneal metaplasia
}

\author{
VOLKER KLAUSS' AND KLAUS RIEDEL ${ }^{2}$ \\ From the 'Section of Ophthalmology, Department of Surgery, University of Nairobi, Kenya, and the \\ ${ }^{2}$ University Eye Hospital, Munich, W. Germany
}

SUMmARY We report on 2 infants, one with a bilateral and the other with a unilateral corneal metaplasia. The first case with bilateral corneal metaplasia showed shortening of both upper and lower lids with formation of symblephara. By ultrasonography the right eye presented with microphthalmos, aphakia, and persistent hyaloid, whereas the inner parts of the left eye appeared to be normal. The question remains to be answered whether this is an abortive cryptophthalmos leading to bilateral corneal metaplasia or a primary corneal metaplasia inhibiting the lid growth. No suggestions concerning the aetiology are made. The second case presented with a unilateral corneal metaplasia, normal eye lids, aphakia, and microphthalmos. This aberration was probably caused by an amniotic band, as it is associated with malformation of the nose on the same side. In case 2 the dermoid was excised and a lamellar corneal graft performed. The histology is reported.

Mesodermal corneal metaplasia is rarely seen. Most cases involving the entire cornea have been reported in the older literature. Hanke ${ }^{1}$ and Wagenmann ${ }^{2}$ termed the disease dermoid or fibrolipoma of the cornea, but Stargardt ${ }^{3}$ stressed that it represents an anomaly and not a neoplasm. We are in fact dealing with a choristomatous lesion. ${ }^{4}$

In mesodermal metaplasia the corneal tissue is transformed into fibrofatty tissue covered by normal skin. The anomaly arises from aberration of the mesoblast between the surface ectoderm and the rim of the optic cup during early embryonic life. ${ }^{3}$ Hanke $^{1}$ also reached this conclusion independently.

Stargardt ${ }^{3}$ divides mesodermal corneal metaplasia into 4 groups. The earlier the malformation occurs during embryonal life the greater will be the damage to the eye.

(1) The metaplasia may protrude out of the palpebral aperture and be pedunculated. The metaplasia also extends from the cornea into the eyeball, inhibiting normal development. Cornea, lens, anterior chamber, iris, and vitreous are not developed, resulting in microphthalmos. The malformations of this group occur before formation of the lens $(4.5 \mathrm{~mm}$ stage $)$.

(2) The metaplasia is of smaller size and involves

Correspondence to Volker Klauss, MD, PO Box 20780. Nairobi. Kenya. the lens but not the posterior parts of the eye. The malformation occurs at the time of formation of the lens ( $12 \mathrm{~mm}$ stage).

(3) The cornea is transformed totally or to a large extent but there is no connection with the lens, which is normally developed. The malformation occurs after formation of the anterior chamber.

(4) Small dermoids of the limbus, occurring as local anomalies of differentiation, are most commonly observed and usually do not interfere with the development of the eyeball.

The cause of the malformation is unknown. It has been suggested that amniotic bands may be responsible $^{356}$ or that a fetal keratitis causes metaplasia of the cornea. ' Combinations of corneal metaplasia with other malformations have been reported, for example, facial clefts ${ }^{13}$ and facial asymmetry with a deviation of the nose. ${ }^{7}$ Henkind $e t$ $a l .{ }^{4}$ reported the only case of hereditary transmission. The last published case report was of a 4-months-old girl with unilateral corneal metaplasia. Penetrating keratoplasty following keratectomy was done with good results. ${ }^{8}$

\section{Case reports}

\section{CASE 1}

A 3-week-old male infant was referred from an outside hospital with bilateral masses filling the 


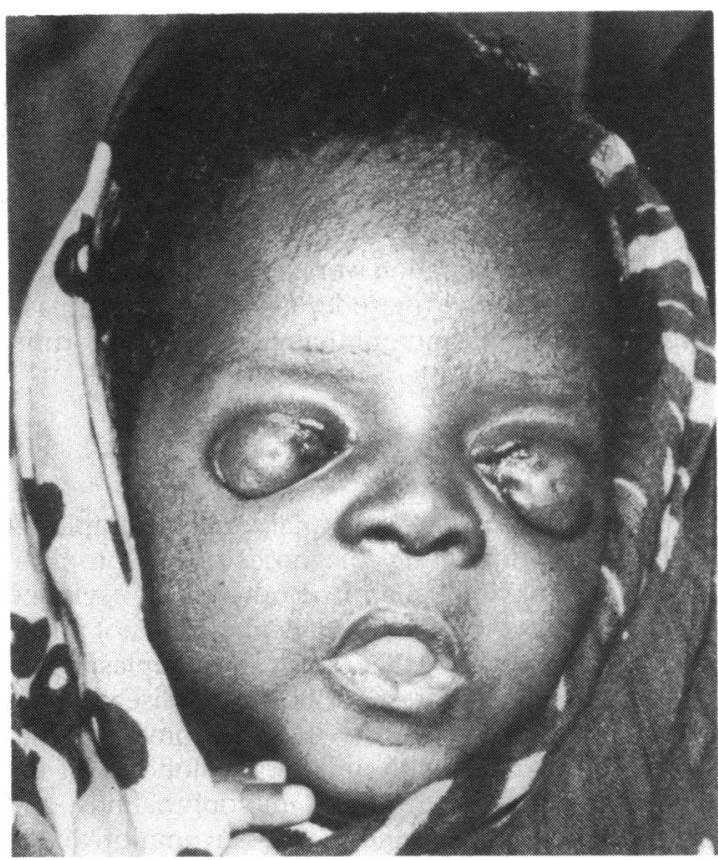

Fig. 1 Case I. Bilateral corneal metaplasia filling the palpebral aperture.

palpebral aperture (Fig. 1). There was no history of malformations in the family; 3 elder brothers and sisters were reported to be healthy. Pregnancy and delivery were normal. The baby presented with short upper and lower lids on both sides. The lids showed little motility. The lid margins were normal in the lower lids and partly in the upper lids on the nasal side, with eye lashes present. Both masses were firmly attached to the lids forming symblephara and filling the palpebral apertures except for small areas close to the inner canthi, where conjunctiva was visible (Fig. 2 ). The masses were firmly attached to the eyeballs, and globes could be palpated. Eye movements were visible. When taking pictures with a flashlight the child blinked, which indicated that there was perception of light. A-scan ultrasonography gave the following result: Right eye: the mass was solid and 2.5 $\mathrm{mm}$ in depth. The length of the eyeball was $15.5 \mathrm{~mm}$ (microphthalmos). High echoes in the centre of the vitreous probably corresponded to a persistent hyaloid. There were no lens echoes. Left eye: the mass was solid and $3 \mathrm{~mm}$ thick. The length of the eyeball was $19 \mathrm{~mm}$. A lens echo was present. There were no echoes in the vitreous, and the retina was found to be attached.

An examination by a paediatrician did not disclose any further abnormality or disease.

Surgical exploration showed normal upper and

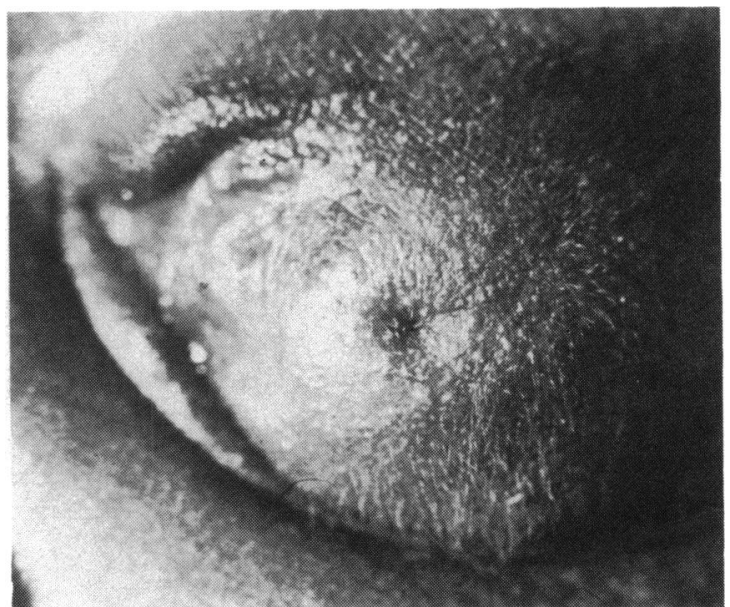

Fig. 2 Case 1. Corneal metaplasia, symblephara. Conjunctiva and lid margins visible near medial canthus. Metaplasia covered with normal skin, showing small hairs. Central umbilication.

lower conjunctival fornices on both sides. The metaplasia originated from deep layers of the cornea. A corneal graft was not considered because of microblepharon and exposure of the cornea. The corneas were covered with buccal mucus in preparation for keratoprosthesis possibly to be done at a later stage.

The diagnosis was bilateral mesodermal corneal metaplasia with microblepharon and symblepharon. Right eye: aphakia, persistent hyaloid, and microphthalmos.

CASE 2

A female child was first brought to our hospital when she was 5 months old. She was the first born. There

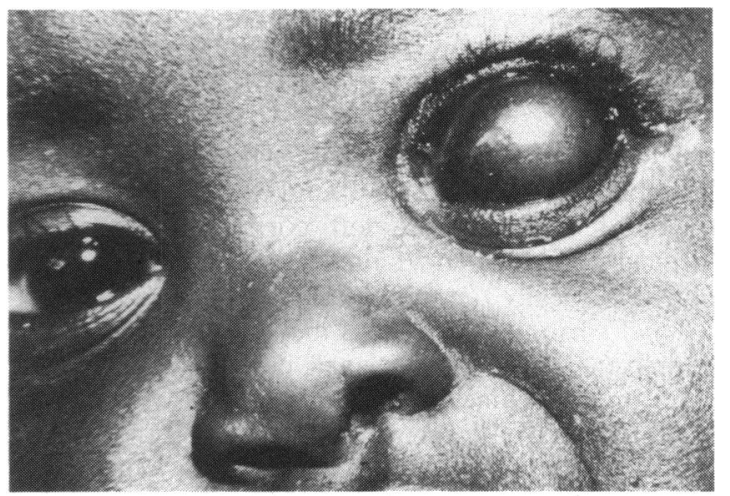

Fig. 3 Case 2. Unilateral corneal metaplasia filling the palpebral aperture. Lids and lid margins not affected. Metaplasia covered with normal skin. Left ala of the nose drawn upwards. 


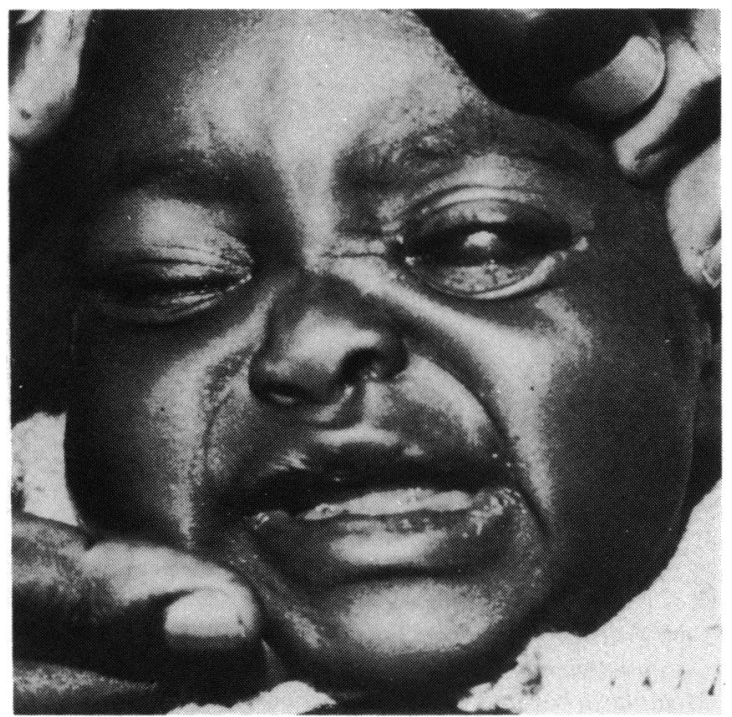

Fig. 4 Case 2. Forced closure of the eyelids when child cries.

was no history of any malformation in the family; pregnancy and delivery were normal. The right eye was normal, showing good light fixation. Left eye: eyebrows and lids were normally developed with eye lashes being present. The palpebral aperture was occupied by a protruding mass that covered the cornea and conjunctiva. The surface of the mass looked like normal skin (Fig. 3). The mass followed eye movements and was not attached to the lids. The lids could almost close on top of the mass, not during normal blinking, but during forced closure when the child cried (Fig. 4). A-scan ultrasonography showed an anteroposterior length of $20 \mathrm{~mm}$ in the right eye. Left eye: the mass was solid and $4 \mathrm{~mm}$ thick. The length of the eyeball was $15.5 \mathrm{~mm}$ (microphthalmos). There were no echoes corresponding to the lens and no echoes in the vitreous. Schirmer's test was $5 \mathrm{~mm}$ in 5 minutes.

The left ala of the nose was drawn upwards (Fig. 3). No other malformation was found by the paediatrician.

The dermoid of the left cornea was removed surgically and a $9 \cdot 0 \mathrm{~mm}$ lamellar graft was performed. Macroscopically the metaplasia arose from the deep corneal stroma; Descemet's membrane appeared to be spared. Through the clear Descemet's membrane anterior synechiae were visible. The histological examination of the excised tissue showed the surface of the metaplasia lined by thick keratinised epithelium (Fig. 5a) with rete ridges. In accordance with the racial pigmentation of the patient the basal epithelial cell layer contained melanin. No Bowman's membrane was evident. The stroma was composed of dense, vascularised collagenous connective tissue and contained many fibroblasts. Small vessels occupied the subepithelial zone, which also contained many skin appendage structures, including sebaceous glands, hair shafts, and follicles (Fig. 5b).

A lamellar keratoplasty was done, and therefore no deeper structures of the cornea for histopathological examination were available.

Diagnosis: left eye: mesodermal corneal metaplasia with aphakia and microphthalmos. Nose deformity left side.

\section{Discussion}

We present 2 cases of mesodermal corneal metaplasia. The possible differential diagnoses are cryptophthalmos and ankyloblepharon. Both can be excluded in our cases, as the lids are well defined and not fused. Von Hippel ${ }^{\text {s }}$ stated that corneal metaplasia and cryptophthalmos represent the same disease with different degrees of severity. He was convinced that in his similar case-with unilateral coloboma of the upper lid, epibulbar dermoid, microphthalmos. and malformations of nose and cheek - an amniotic band inhibited the lid growth. He believed that larger amniotic bands lead to cryptophthalmos whereas smaller ones present with short lids, as in our first case, or in colobomas.

Hanke $^{1}$ described a case of unilateral corneal metaplasia associated with microphthalmos, aphakia, and normal lids, thus resembling our case 2 . Wagenmann ${ }^{2}$ reported a unilateral case in which a rudimentary eyeball was embedded in a huge dermoid. Histologically he found a persistent hyaloid, as we did on ultrasonography of the right eye of our first case. Ida Mann' reported a case of a Hindu child from Bombay in 1930. The photograph shows a strong resemblance to our case 2 . The lids and lashes were normal. Histological examination revealed the absence of conjunctiva, iris, and lens. The metaplasia extended into the inner eye. She placed the onset of the aberration at the fourth week of development but did not discuss the aetiology. Nor did Duke-Elder ${ }^{10}$ commit himself on the aetiology. He mentioned a case published by Mehta that resembles Mann's." Hanke's, ${ }^{1}$ and our second case. Sinha and Mishra ${ }^{11}$ described a case of bilateral dermoid arising from the limbus but not covering the entire cornea.

According to Stargardt's $s^{3}$ classification the right eye of our case 1 belongs to group 1 , as there is aphakia, persistent hyaloid, and microphthalmos on ultrasonography. The left eye of the same case would correspond to group 3, as the inner eye appears normal. This indicates that the onset of this externally symmetrical lesion must have occurred at slightly different periods of development. 


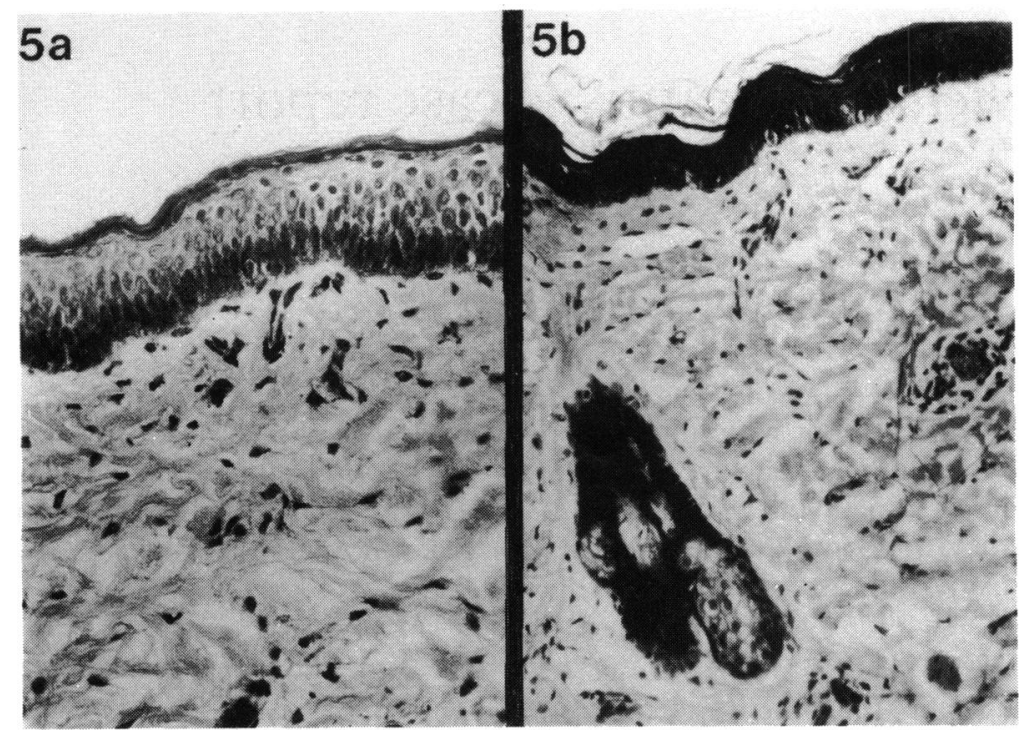

Fig. 5 Case 2. (a) Keratinised epithelium with absence of Bowman's membrane (Haematoxylin and eosin, $\times 53$ ). (b) Vascularisation of the collagenous connective tissue and skin appendage structures. (Haematoxylin and eosin, $\times 34$ ).

One question about our case 1 remains to be answered. Is it a primary deformity of the lids -an abortive cryptophthalmos-with secondary metaplasia of the cornea, or is it a case of primary metaplasia of the cornea inhibiting the growth of the lids and leading to the formation of symblephara? We cannot answer this question and have no suggestion concerning the aetiology of the malformation in case 1 .

In case 2 the metaplasia may have been caused by an amniotic band, as the lesion is unilateral and associated with a malformation of the left ala of the nose.

For technical reasons a chromosome study could not be done in either case.

\section{References}

1 Hanke V. Zwei seltene Missbildungen des Bulbus. Albrecht von Graefes Arch Klin Ophthalmol 1904; 57: 28-52.
2 Wagenmann A. Ueber einen merkwuerdigen Fall von Dermoidgeschwulst mit rudimentärer Entwicklung des Auges. Albrecht von Graefes Arch Klin Ophthalmol 1889; 35: 111-44.

3 Stargardt $K$. Ueber eine seltene Missbildung am Auge. $Z$ Augenheilkd 1917; 37: 25-42.

4 Henkind P. Marinoff G. Manas A. Friedman A. Bilateral corneal dermoids. Am J Ophthalmol 1973: 76: 972-7.

5 v. Hippel E. Epibulbäres Dermoid, Lidcolobom und Mikrophthalmus. Albrecht von Graefes Arch Klin Ophthalmol 1906; 63: 38-45.

6 Velhagen K. ed. Der Augenarzt. 2nd ed. Leipzig: Thieme, 1975: 3: 857-9.

7 Stoll KL. A case of multiple double lipodermoids of the conjunctivae and cornea. accompanied by intrabulbar and other anomalies. Am J Ophthalmol 1913; 30: 1-14.

8 Zaidmann GW, Johnson B. Brown St J. Corneal transplantation in an infant with dermoid. Am J Ophthalmol 1982;93: 78-83.

9 Mann I. A rare congenital abnormality of the eye. Br J Ophthalmol 1930; 14: 321-30.

10 Duke-Elder S. Normal and abnormal development: congenital deformities. In: System of Ophthalmology. London: Kimpton. 1964: 3: 535-8.

11 Sinha PN. Mishra MB. Corneal dermoid. Am J Ophthalmol 1950; 33: $1137-41$. 